\title{
The Effect of House Dust Mite Immunotherapy, Probiotic and Nigella sativa in The Number of Th17 Cell and Asthma Control Test Score
}

\author{
Astrid Kristina Kardani ${ }^{1}$, Loeki Enggar Fitri ${ }^{2}$, Wisnu Barlianto ${ }^{3}$, Ery Olivianto ${ }^{4}$, \\ HMS Chandra Kusuma ${ }^{4}$ \\ ${ }^{1}$ Biomedical Science Master Study Program/Pediatric Specialist Study Program, Faculty of Medicine University \\ of Brawijaya/dr. Saiful Anwar Hospital, Indonesia \\ ${ }^{2}$ Parasitology Department, Faculty of Medicine University of Brawijaya, Indonesia. \\ ${ }^{3}$ Allergy-Immunology Division-Pediatric Department, Faculty of Medicine University of Brawijaya/dr. Saiful \\ Anwar Hospital, Indonesia \\ ${ }^{4}$ Respirology Division-Pediatric Department, Faculty of Medicine University of Brawijaya/dr. Saiful Anwar \\ Hospital, Indonesia
}

\begin{abstract}
The Role of Th17 cells in the pathogenesis of asthma and immunotherapy is being a new concept and paradigm. Immunotherapy on asthma requires long periods of time, so administration of an adjuvant had been considered to improve its efficacy. The aims of this study was to evaluate the therapeutic efficacy of immunotherapy combined with probiotics and Nigella sativa in the number of Th17 cells and the improvement of clinical symptoms of asthma. A total of 31 children with mild asthma were evaluated and then randomized to receive immunotherapy or immunotherapy plus Nigella sativa or immunotherapy plus probiotic or immunotherapy plus Nigella sativa plus probiotic openly for 14 weeks. Statistical analysis found no significant difference in the mean number of Th17 cells pre and post test in all four treatment groups, however we found a significant differences asthma control test (ACT) score before and after the immunotherapy + Nigella sativa treatment $(p=0.001)$, before and after immunotherapy + probiotic treatment $(p=0.004)$, as well as before and after immunotherapy plus Nigella sativa plus probiotic treatment $(p=0.000)$. Correlation test found a significant association between the number of Th17 cells and ACT score in all groups. The combination immunotherapy with Nigella sativa and probiotics did not reduce the number of peripheral blood Th17 cells mild asthmatic children, but can improve the clinical symptom.
\end{abstract}

Keywords - Immunotherapy, House dust mite, Probiotics, Nigella sativa, Th17 cell, Asthma Control test

\section{Introduction}

In the last 30 years, the concept of chronic inflammation is considered to play an important role in the pathogenesis of asthma. This process is dominated by the activity of cells that secrete Th2 cytokines IL-4, IL-5, IL-9, and IL-13 [1]. The concept of the balance of Th1 and Th2 cells become a basic molecular mechanisms of the immune response in asthma. Balance of Th1 and Th2 cytokine production is more important than the absolute amount or concentration of cytokines themselves [2]. For two decades, this theory is believed by experts until the discovery of new effector T cells, regulatory T cells (Treg) and Th17 cells [3].

The role of Th17 cells that produce IL-17 in the pathogenesis of asthma is now being a new concept and paradigm. Studies on the involvement of Th17 cells and its role in allergic and autoimmune diseases had been developed as well as protective functions against bacterial and viral infections. This function was previously believed to be mediated by Th1 and Th2 cells. Interleukin-17 was found to increase in lung tissue, broncho alveolar lavage fluid (BAL), sputum, and peripheral blood of patients with asthma. In sputum of asthma patients, an increasing number of Th17 cells are associated with neutrophil number and incidence of severe asthma symptoms [4]. Interleukin-17 can stimulate the release of neutrophils and eosinophils which can induce airway hyper-reactivity, broncho-constriction, mucus secretion, and airway remodeling. Therefore, it can be said Th17 cells and IL-17 associated with asthma severity [5].

House dust mite is a major allergen of asthma and rhinitis in children [6-10]. House dust mite specific immunotherapy with subcutaneous or sublingual method aims to achieve immune tolerance to HDM [11]. Nurhayati et al (2011) reported that administration of subcutaneous specific immunotherapy HDM can improve clinical symptoms of asthma and allergic rhinitis in children [12]. Immunotherapy has a modulating effect on $\mathrm{T}$ cells by inducing a shift towards Th2 to Th1 cell activity [10]. Provision of immunotherapy in children with asthma can affect the balance of Th1, Th2, Th17, and Treg cells activities. The principle mechanism of immunotherapy is through induction of peripheral $\mathrm{T}$ cell tolerance and Treg cell stimulation that can influence all the effector T cells including Th1, Th2, and Th17 [13]. 
Based on the World Health Organization (WHO), probiotics are live microorganisms which when administered in adequate amounts would be beneficial to human health [14]. Clinical studies of the effects of probiotics in asthma remains controversial [15]. Jinho et al (2010) mentions that Lactobacillus casei rhamnosus Lcr35 can improve airway inflammation and hyper-reactivity in mouse asthma models. [16]. However according to Endaryanto et al (2009), specific HDM sublingual immunotherapy plus probiotics can reduce the number of eosinophils, levels of immunoglobulin $\mathrm{E}$ (IgE), and modulates the balance of Th1 and Th2 cytokines [17]. Yue-sheng et al (2010) also reported that administration of Lactobacillus gasseri on 105 children aged 612 years who had mild persistent asthma and rhinitis can improve clinical symptoms and forced expiratory volume in 1 second (FEV1) [18].

Black cumin seeds (Nigella sativa) has been used in traditional medicine for the treatment of various diseases including diarrhea and asthma [19]. Thymoquinone (TQ) that is contained in the Nigella sativa seeds has anti-oxidant, anti-inflammatory, anti-histamine, bronchodilators, and immunomodulatory immune response [20]. Several studies have shown the benefits of Nigella sativa seeds in improving the symptoms of asthma and allergic rhinitis [21,22]. Barlianto et al (2012) reported that administration of Nigella sativa can increase the number of lymphocytes T CD4 + CD25 + FoxP3 +, inhibits airway remodeling, and modulate the immune response in murine models of asthma [23]. While Ahmad et al (2010) found an improvement in peak expiratory flow rate (PEFR) after administration of Nigella sativa in children aged 5-15 years who suffer from lower respiratory tract infections with wheezing [24].

The goal of asthma management is currently more focused on asthma control. The success of the asthma control can be assessed with the scoring system. One of the commonly used scoring system has been validated is asthma control test (ACT). Asthma control test (ACT) can be used easily in handling day-to-day asthma patients because of the scoring system without including measurement of lung function [25-29].

Immunotherapy requires long periods of time, so this raises the number of patients who dropped out during the administration of immunotherapy. Therefore, an adjuvant immunomodulator administration is necessary to improve the effectiveness of immunotherapy. Previous study suggests that probiotics has immunomodulating effect that can reduce the inflammatory process induced by food allergies [30]. House dust mite specific provision in sublingual immunotherapy in combination with probiotics compared with probiotic treatment only, was equally effective in reducing the symptoms of asthma in 6-17 years aged of asthma children [31]. The addition of probiotics, Nigella sativa also has potential as an immunomodulatory and antiinflammatory effects. The provision of Nigella sativa in allergic rhinitis patients that receive specific immunotherapy HDM increased the effectiveness of immunotherapy [32]. Based on this, this study will evaluate the efficacy of the combination of HDM specific immunotherapy, probiotics, and Nigella sativa in influencing the number of Th17 cells and clinical scoring of asthma in children.

\section{Methods}

This study was an experimental research, randomized clinical trial (RCT), single-blind, pre and post test control group. A total of 31 children with mild asthma were evaluated and then randomized to 4 groups, there are group that receive immunotherapy, group that receive immunotherapy plus Nigella sativa, group that receive immunotherapy plus probiotic and group that receive immunotherapy plus Nigella sativa plus probiotic openly for 14 weeks. The samples were pediatric patients diagnosed with asthma and underwent outpatient Allergy and Immunology clinic of dr. Saiful Anwar hospital, Malang during the period August to December 2012 that meet the inclusion and exclusion criteria.

Inclusion criteria for this study sample include children diagnosed with asthma based on national guidelines for childhood asthma for children aged $\geq 5$ years and asthma predictive index (IPA) for children $<5$ years, and classified the degree of intermittent or mild persistent asthma based on global criteria initiative for asthma (GINA), aged 4-14 years, allergic to house dust mite by skin prick test results., had never received previous immunotherapy, the patient's parents volunteered to follow the study and signed an informed consent.

The exclusion criteria were patients with asthma who take cytostastica, accompanied by co-morbid asthma patients such as sinusitis, otitis media, tuberculosis, pneumonia, nasal polyps, gastro-esophageal reflux, or other anatomical abnormalities, patients suffering from immunodeficiency, autoimmune diseases, or have cardiovascular abnormalities, a history of severe allergies such as asthma attacks and anaphylactic shock, lifethreatening asthma, had suffered from respiratory failure or been intubated in the last 5 years, patients taking therapeutic doses of corticosteroids during the 1 - 2 weeks, vitamin D3 doses of more than 2000 IU / day for 34 months, $\beta$ blockers, angiotensin-converting enzyme (ACE), leukotriene antagonists, teofillin, anti-cholinergic, cromolyn and ketotifen in the 2 weeks before and during the study, patients with asthma who smoked actively or passive smoking, asthma exacerbations or respiratory tract infection within the last 30 days.

The drop out criteria in this study are: patients who not come in immunotherapy schedule for 3 consecutive weeks during the induction phase of immunotherapy and should repeat the initial dose, patients do not take probiotics and/or Nigella sativa as recommended by the researchers, patients were eligible exclusion for 
observational studies, and patients who experience severe side effects such as anaphylactic shock due to treatment delivery.

During the build-up phase, an injection at a dose of allergen is increased in order to obtain the target dose. In this study, immunoalergen HDM was produced by pharmaceutical Installing Dr. Soetomo hospital. Each vial contains $5 \mathrm{ml}$ and contained $5 \mathrm{mg} / \mathrm{ml}$ of HDM. House dust mite specific immunotherapy was given to asthmatic patients with results of skin prick test proved HDM allergic. Immunotherapy is given every week for 14 weeks using liquid III (mixture of HDM allergens and Cocca filtra) with increased dose per week. Dilution immunotherapy extracts given in this phase is 1:100. The dose given during this phase increased gradually each week until the maintenance dose is reached. This protocol is based on immunotherapy guidelines of dr. Saiful Anwar Hospital Malang.

Table 1. Immunotherapy dose in buid up phase

\begin{tabular}{|cccc|}
\hline Week & Dose $(\mathbf{m l})$ & Week & Dose $(\mathbf{m l})$ \\
\hline \hline 1 & 0,1 & 8 & 0,1 \\
2 & 0,15 & 9 & 0,15 \\
3 & 0,22 & 10 & 0,22 \\
4 & 0,32 & 11 & 0,32 \\
5 & 0,48 & 12 & 0,48 \\
6 & 0,72 & 13 & 0,72 \\
7 & 1 & 14 & 1 \\
\hline
\end{tabular}

Probiotics which used in this study is PROBI ${ }^{\circledR}$ of Medifarma, containing $2 \times 10^{9} \mathrm{cfu} / \mathrm{g}$ mixed bacteria Lactobacillus acidophilus LA life- $5^{\mathrm{TM}}$ and Bifidobacterium lactis $\mathrm{Bb}-12^{\mathrm{TM}}$, vitamin premix (vitamin $\mathrm{B}_{1} 0,1 \mathrm{mg}$, vitamin $\mathrm{B}_{2} 0,1 \mathrm{mg}$, vitamin $\mathrm{B}_{6} 0.1 \mathrm{mg}$, vitamin $\mathrm{C} 3 \mathrm{mg}$ ), and selenium yeast $1 \mathrm{mg}$ with the dose is 1 sachet per day. Nigella sativa were used in this study was Nigella sativa in powder form and in capsules prepared and was given at a dose of $15 \mathrm{mg} / \mathrm{kg} /$ day [33]. Each capsule contains $150 \mathrm{mg}$ of Nigella sativa. Each $10 \mathrm{~kg}$ of weight will receive 1 capsule Nigella sativa. The Examination of the number of Th17 cells by flowcytometry using PMBC isolation from peripheral blood. The number of TH17 cells were counted subsequently analyzed using BD Cell quest Pro software.

In this study, data analysis techniques will be performed six stages of counting, respectively: (1) test the validity and reliability of the questionnaire, (2) test the normality of the data sample with KolmogorovSmirnov test, (3) one-way ANOVA test for sample data pretest, (4) paired sample t test for pretest-posttest sample data, (5) one-way ANOVA test to post-test sample data, and (6) Pearson correlation test. All calculations performed with the software of SPSS for Windows 19.0.

\section{Results}

Each treatment group consisted of 8 samples were subsequently undergoing immunotherapy for 14 weeks. Group 1 consisted of 8 samples was given immunotherapy and placebo for 14 weeks. In the $4^{\text {th }}$ week, one sample was excluded from the study because did not come three times in a row to undergo immunotherapy. The groups 2, 3, 4, each consisted of 8 samples were receive of immunotherapy plus Nigella sativa, immunotherapy plus probiotics and immunotherapy plus Nigella sativa plus probiotics. All samples of this three groups always come on time and do not have drop out patient. During the period of observation and treatment for 14 weeks, there was no one of the patients obtained any side effects of immunotherapy. Characteristics of the sample data are presented in Table 1 .

Table 1. Baseline characteristics of sample

\begin{tabular}{lcccc}
\hline Characteristics & Group 1 $(\mathrm{n}=7)$ & $\begin{array}{c}\text { Group } 2 \\
(\mathrm{n}=8)\end{array}$ & Group 3 (n=8) & Group 4 (n-8) \\
\hline $\begin{array}{l}\text { a. Age } \\
\text { < 5 years }\end{array}$ & $1(14.3 \%)$ & $3(37.5 \%)$ & $2(25 \%)$ & $1(12.5 \%)$ \\
$\geq 5$ years & $6(85.7 \%)$ & $5(62.5 \%)$ & $6(75 \%)$ & $7(87.5 \%)$ \\
\hline b. Sex & & & \\
-Boy & $4(57.1 \%)$ & $4(50 \%)$ & $4(50 \%)$ & $5(62.5 \%)$ \\
-Girl & $3(42.9 \%)$ & $4(50 \%)$ & $4(50 \%)$ & $3(37.5 \%)$ \\
\multicolumn{5}{c}{ www.iosrjournals.org } \\
\end{tabular}




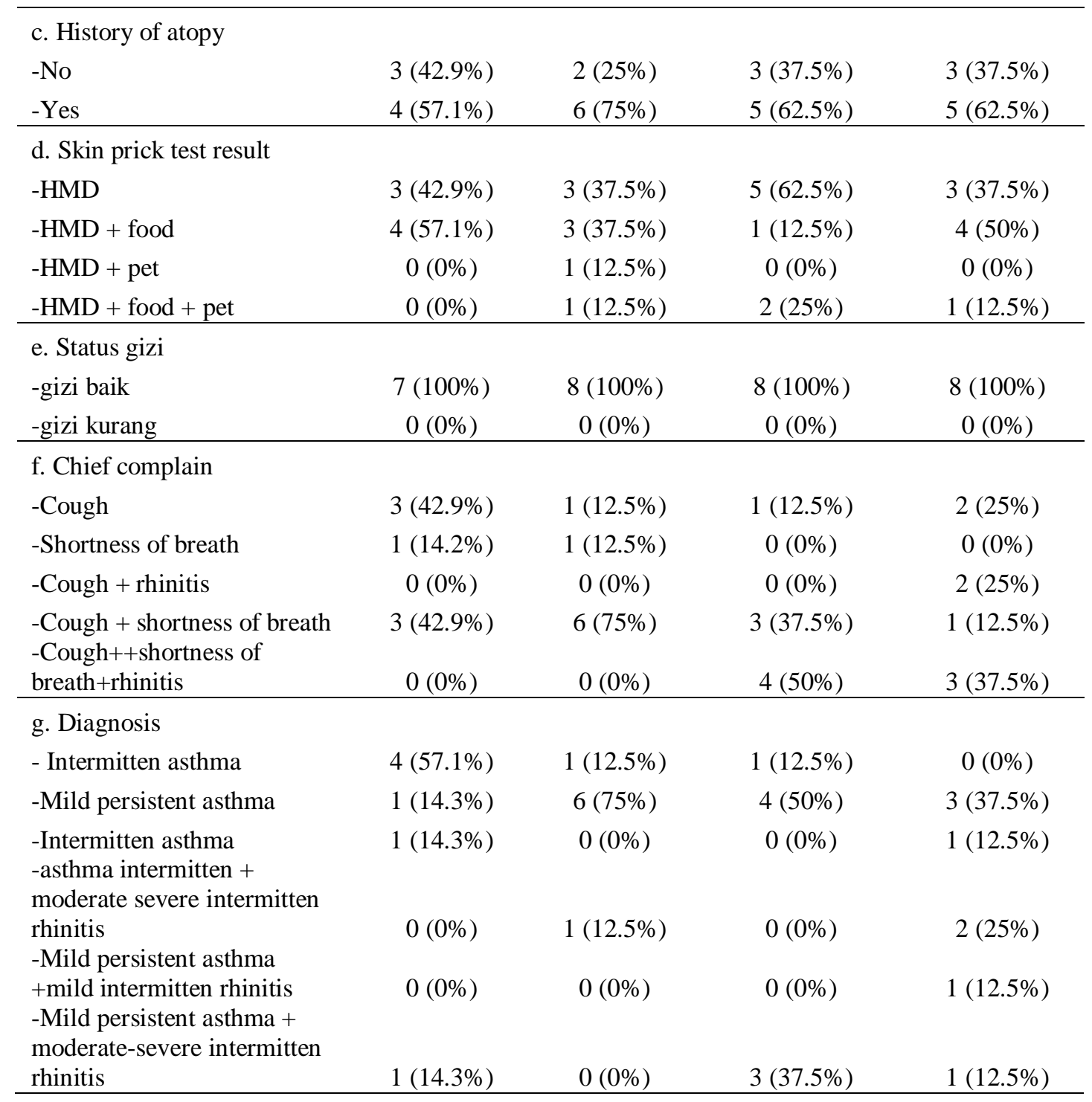

One-way ANOVA test results were shown in Table 2 and Table 3.There was no significant difference (p-value $=0.934>\alpha$ ) pretest mean number of Th17 cells and the ACT among treatment groups with the administration of immunotherapy, immunotherapy plus Nigella sativa, immunotherapy plus probiotics, and immunotherapy plus Nigella sativa plus probiotics.

Table 2. Comparrison of Th17 cells before treatment

\begin{tabular}{lll}
\hline Groups & $\begin{array}{l}\text { Mean } \pm \\
\text { stan.dev }\end{array}$ & $\begin{array}{l}\text { p-value } \\
\text { (Anova) }\end{array}$ \\
\hline Immunotherapy & $15.86 \pm 5.15$ & \\
Immunotherapy + Nigella sativa & $16.00 \pm 2.73$ & \\
& & $0.980>\propto$ \\
Immunotherapy + probiotics & $15.75 \pm 1.67$ & \\
immunotherapy+Nigella & $15.38 \pm 1.60$ & \\
sativa+probiotics & & \\
\hline
\end{tabular}




\begin{tabular}{lcc}
\multicolumn{3}{c}{ Table 3 Comparrison of ACT before treatment } \\
\hline Groups & $\begin{array}{c}\text { Mean } \pm \\
\text { stan.dev }\end{array}$ & $\begin{array}{c}\text { p-value } \\
\text { (Anova) }\end{array}$ \\
\hline Immunotherapy & $0.37 \pm 0.34$ & \\
Immunotherapy + Nigella sativa & $0.48 \pm 0.52$ & \\
Immunotherapy + probiotics & $0.42 \pm 0.28$ & $0.934>\propto$ \\
immunotherapy+Nigella sativa+probiotics & $0.39 \pm 0.19$ & \\
\hline
\end{tabular}

If $p$-value $<0.05$, it mean there is a significance difference

In group 1, group that given immunotherapy plus placebo, 7 patiens were evaluated for the number of Th17 cells and ACT score before and after treatment. Table 4 illustrates that there was no significant difference in the mean number of Th17 cells ( $\mathrm{p}$-value $=0.599>\alpha)$ between pretest $(0: 37 \pm 0: 34 \%)$ and posttest $(0.31 \pm$ $0: 11 \%$ ) of administering immunotherapy group. This means that immunotherapy treatment in children with mild asthma will not affect the number of Th17 cells. Similarly, the mean ACT values between pretest $(15.86 \pm$ $5.15 \%)$ and posttest $(18.00 \pm 7: 42 \%)$ of administering immunotherapy group showed no significant difference $(\mathrm{p}$-value $=0.062>\alpha)$. It could be argued that the administration of immunotherapy in children with mild asthma will not affect the ACT.

Table 5 showed that there was no significant difference in the mean number of Th17 $(\%)(\mathrm{p}$-value $=$ $0.290>\alpha)$ between pretest $(0.48 \pm 0.52 \%)$ and postest $(0: 24 \pm 0: 18 \%)$ of administering immunotherapy + Nigella sativa group. This means that the administration of immunotherapy treatments + Nigella sativa in children with mild asthma will not affect the number of Th17. In contrast, there was a very significant differences in mean of ACT score $(\mathrm{p}$-value $=0.001<\alpha)$ between pretest $(16.00 \pm 2.73 \%)$ and posttest $(20.75 \pm$ $3: 37 \%)$ of administering immunotherapy + Nigella sativa group. This means that the administration of immunotherapy + Nigella sativa in children with mild asthma will affect the ACT, which is able to increase the ACT.

Table 4. Comparison of Th17 cells and ACT before e $\&$ after immunotherapy + Nigella sativa treatment

\begin{tabular}{llll}
\hline Variable & $\begin{array}{l}\text { pretest } \\
\text { mean } \pm \text { SD }\end{array}$ & $\begin{array}{l}\text { posttest } \\
\text { mean } \pm \text { SD }\end{array}$ & $\begin{array}{l}\boldsymbol{p} \text { - } \\
\text { value }\end{array}$ \\
\hline Th17 $(\%)$ & $0.48 \pm 0.52$ & $0.24 \pm 0.18$ & 0.290 \\
& & & \\
ACT & $16.00 \pm 2.73$ & $20.75 \pm 3.37$ & 0.001 \\
\hline
\end{tabular}

Table 5. Comparison of Th17 cells and ACT and after immunotherapy treatment

\begin{tabular}{llll}
\hline Variable & $\begin{array}{l}\text { Pretest } \\
\text { mean } \pm \text { SD }\end{array}$ & $\begin{array}{l}\text { Posttest } \\
\text { mean } \pm \text { SD }\end{array}$ & p-value \\
\hline Th17 $(\%)$ & $0.37 \pm 0.34$ & $0.31 \pm 0.11$ & 0.599 \\
ACT & $15.86 \pm 5.15$ & $18.00 \pm 7.42$ & 0.062 \\
\hline
\end{tabular}

In Table 6, explaining that there was no significant difference in the mean number of Th17 cells (pvalue $=0564>\alpha)$ between sample groups by prior administration of immunotherapy + probiotics $+(0.42 \pm$ $0: 28 \%)$ and after administration of immunotherapy + probiotic $(0.52 \% \pm 0: 31)$. This means that the administration of immunotherapy + probiotic in children with mild asthma will not affect the number of Th17 cells. However, there was a very significant differences in mean of ACT ( $\mathrm{p}$-value $=0.004<\alpha$ ) between pretest $(15.75 \pm 1.67 \%)$ and posttest $(21: 00 \pm 3.82 \%)$ of administering immunotherapy + probiotic group. This means that the administration of immunotherapy + probiotic in children with mild asthma will affect the ACT, which is able to increase the ACT.

In Table 7 explains that there was no significant difference in the mean number of Th17 cells (p-value $=0.355>\alpha)$ between pretest $(0.39 \pm 0.19 \%)$ and posttest $(0.47 \pm 0.23 \%)$ of administering immunotherapy + Nigella sativa + probiotics group. This means that the provision of immunotherapy treatments + Nigella sativa + probiotics in patients with mild asthma children will not affect the number of Th17 cells. However, there was a very significant differences in mean of ACT of administering immunotherapy + Nigella sativa + probiotic sample group $(\mathrm{p}$-value $=0.000<\alpha)$ before $(15: 38 \pm 1.60 \%)$ and after $(20: 50 \pm 2: 07 \%)$ treatment. This means that 
the provision of immunotherapy treatments + Nigella sativa + probiotics in patients with mild asthma children will affect the ACT, which is able to increase the ACT.

Table 6. Comparison of Th17 cells and ACT before

\begin{tabular}{llll}
\hline Vari & $\begin{array}{l}\text { pretest } \\
\text { mean } \pm \text { SD }\end{array}$ & $\begin{array}{l}\text { postest } \\
\text { mean } \pm \text { SD }\end{array}$ & $\begin{array}{l}\boldsymbol{p} \text { - } \\
\text { value }\end{array}$ \\
\hline Th17 $(\%)$ & $0.39 \pm 0.19$ & $0.47 \pm 0.23$ & 0.355 \\
ACT & $15.38 \pm 1.60$ & $20.50 \pm 2.07$ & 0.000 \\
\hline
\end{tabular}

Table 7. Comparison of Th17 cells and ACT before \& after immunotherapy + probiotics treatment and after immunotherapy+Nigella sativa+probiotics

\begin{tabular}{llll}
\hline Variable & $\begin{array}{l}\text { pretest } \\
\text { mean } \pm \text { SD }\end{array}$ & $\begin{array}{l}\text { posttest } \\
\text { mean } \pm \text { SD }\end{array}$ & $\begin{array}{l}\boldsymbol{p} \text { - } \\
\text { value }\end{array}$ \\
\hline Th17 $(\%)$ & $0.42 \pm 0.28$ & $0.52 \pm 0.31$ & 0.564 \\
$\mathrm{ACT}$ & $15.75 \pm 1.67$ & $21.00 \pm 3.82$ & 0.004 \\
\hline
\end{tabular}

Based on the results of one-way ANOVA test, there was no significant difference ( $\mathrm{p}$-value $=0.061>\alpha$ ) the mean number of Th17 cells among four groups after the treatments (posttest). In other words, the administration of immunotherapy, immunotherapy plus Nigella sativa, immunotherapy plus probiotics, immunotherapy plus Nigella sativa plus probiotics in children with mild asthma have the same effect on the number of Th17 cells. Based on the value of the mean, there was an increasing number of Th17 cells in the sample group with immunotherapy plus probiotic and immunotherapy plus Nigella sativa plus probiotics in children with mild asthma when compared to children with only the administration of immunotherapy or immunotherapy plus Nigella sativa, though the increase is not statistically significant (figure 1). Figure 2 also show the comparison of Th17 cells before and after treatment in four groups.

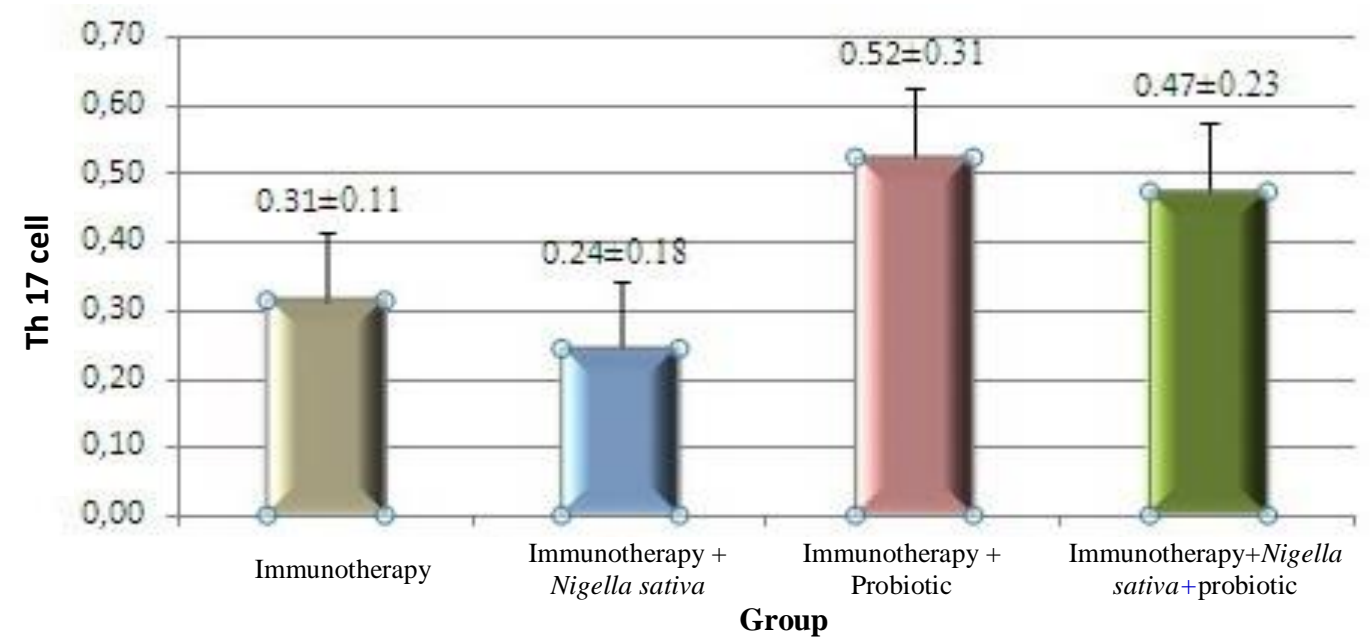

Figure 1. The difference of Th17 mean after treatment (posttest)

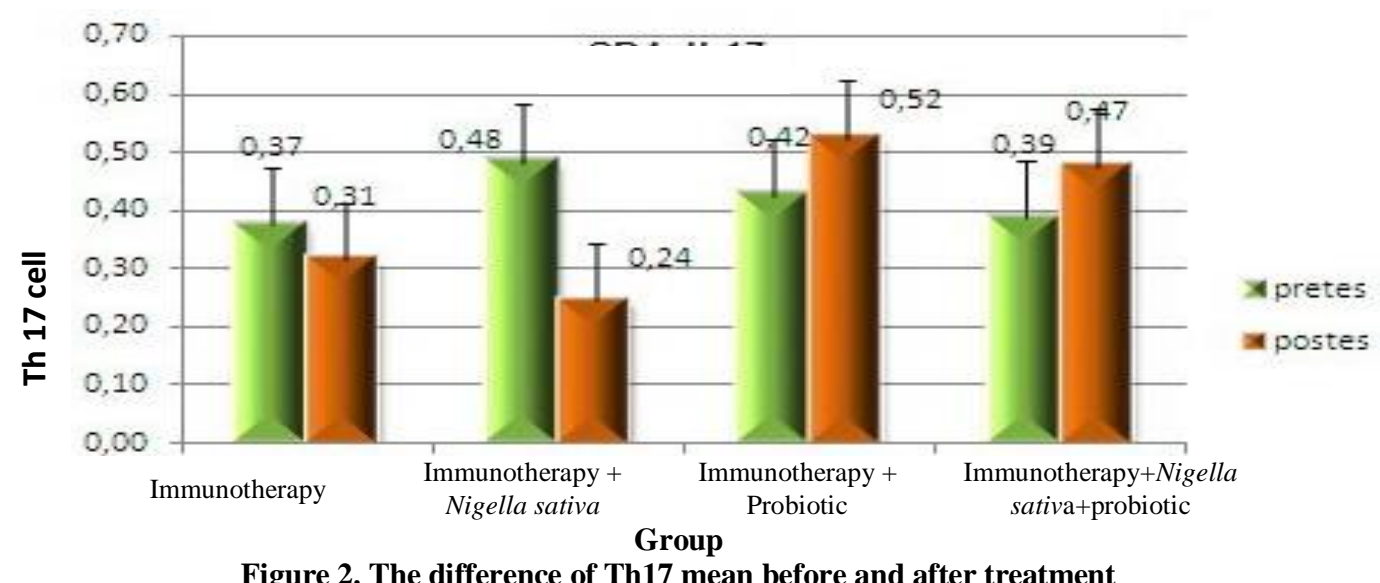

Figure 2. The difference of Th17 mean before and after treatment 
In Figure 3 below showed that there was no significant difference ( $p$-value $=0562>\alpha$ ) of posttest mean ACT among four treatment groups. The administration of immunotherapy, immunotherapy plus Nigella sativa, immunotherapy plus probiotics, and immunotherapy plus Nigella sativa plus probiotics in children with mild asthma have the same impact on the ACT. There was an increasing of ACT score in the treatment group with immunotherapy plus Nigella sativa, immunotherapy + probiotics, and immunotherapy plus Nigella sativa a plus probiotics in children with mild asthma when compared with group that received of immunotherapy only, even this increasing is not statistically significant. Figure 4 shows the comparison of ACT mean before and after treatment in four groups.

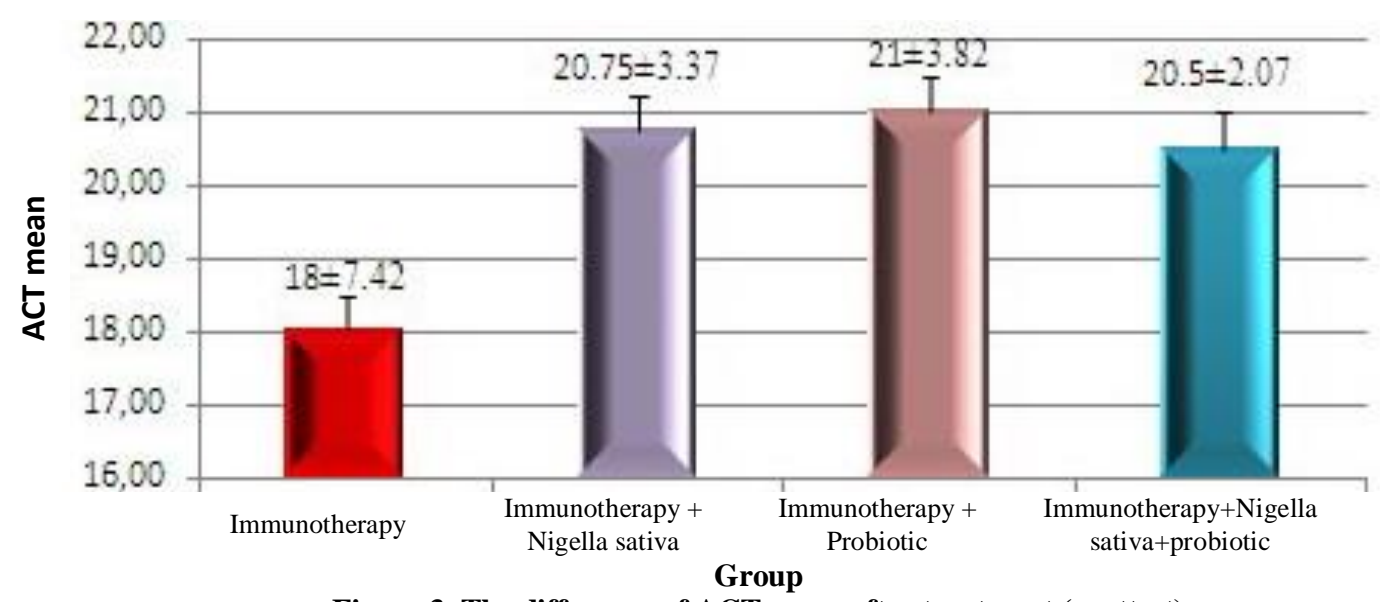

Figure 3. The difference of ACT mean after treatment (posttest)

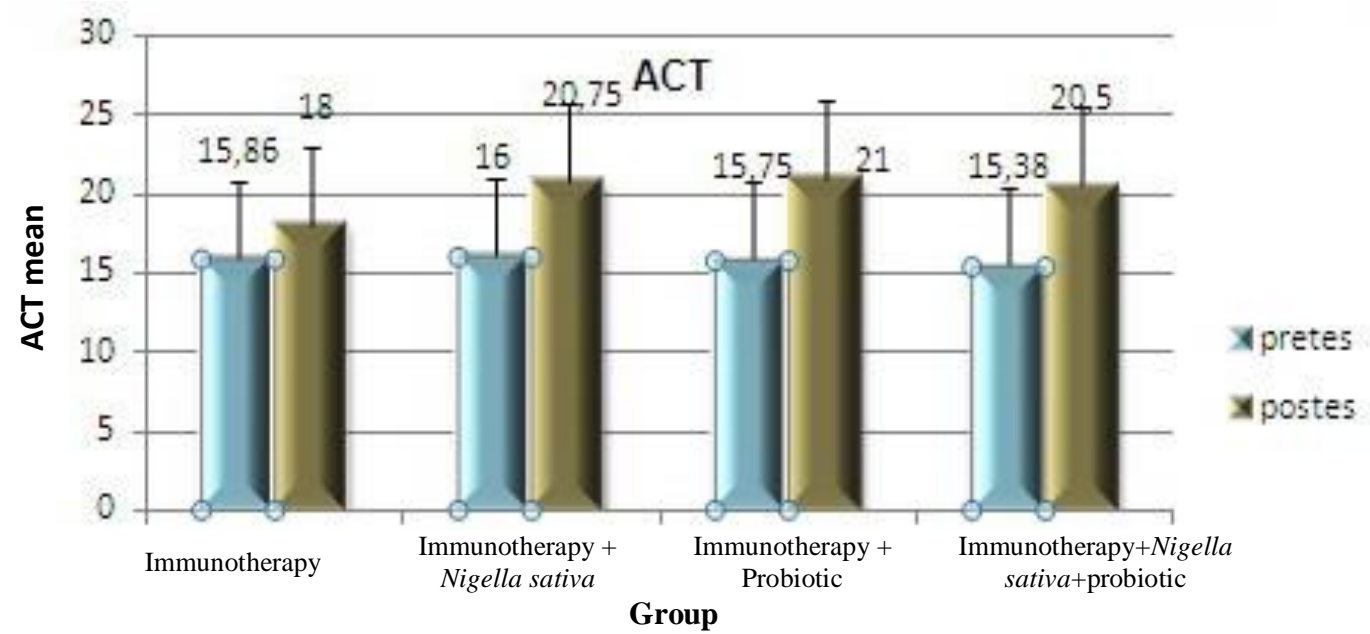

Figure 4. The difference of ACT mean before and after treatment

Table 8 below shows that there was a significance relationship between the number of Th17 cells with ACT score $(p$-value $=0.012<\alpha)$ in the immunotherapy group, indicated level of closeness of relationship (correlation coefficient) which was very powerful (-0863). Negative values indicate the opposite relationship exists, ie if there is an increase in the number of Th17 cells there will be a decrease in the ACT in children with mild asthma, or vice versa. Table 9 also shows that there was a relationship between the number of Th17 cells and ACT with highly significant $(\mathrm{p}$-value $=0.002<\alpha)$ in immunotherapy plus Nigella sativa group.

Table 8. The correlation between Th17cells and ACT in immunotherapy group

\begin{tabular}{lll}
\hline Variable & $\begin{array}{l}\text { Correlation coefficient } \\
(\mathrm{r})\end{array}$ & p-value \\
\hline Th17 & -0.863 & 0.012 \\
\hline ACT & -0.980 & 0.000 \\
\hline
\end{tabular}

Table 9. The correlation between Th17 cells and ACT in immunotherapy + Nigella sativa group.

\begin{tabular}{lll}
\hline Variable & $\begin{array}{l}\text { Correlation coefficient } \\
(\mathrm{r})\end{array}$ & p-value \\
\hline Th17 & -0.899 & 0.002 \\
\hline ACT & -0.924 & 0.001 \\
\hline
\end{tabular}

Table 10 shows that there was a significance relationship between the number of Th17 with ACT score ( $\mathrm{p}$-value $=0.001<\alpha)$ in the immunotherapy plus probiotic group with level of closeness of relationship (correlation coefficient) is very powerful is -0923 . Negative values indicate the opposite relationship exists, ie if 
there is an increase in Th17 there will be a decrease in the ACT in patients with mild asthma child, or vice versa. Table 11 also shows the same result in immunotherapy plus Nigella sativa plus probiotic groups. There was a significance relationship $(\mathrm{p}$-value $=0.001<\alpha$ ) and correlation coefficient was -0931 .

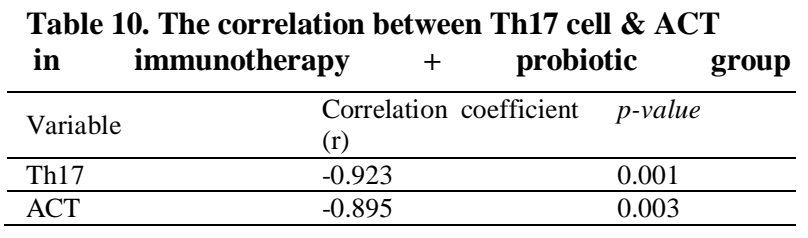

\section{Discussion}

The result showed that there was no statistically significant difference in the number of Th17 cells among four groups. This is not in accordance with previous studies, Eifan et al (2010) which states immunotherapy has a modulating effect on T cells by inducing Th2 cell activity shifts towards to Th1 cells that diminish the symptoms of asthma and rhinitis [10]. Provision of immunotherapy in children with asthma can affect the balance of Th1 cell activity, Th2, Th17, and Treg. The principle mechanism of immunotherapy is through induction of peripheral $\mathrm{T}$ cell tolerance and Treg stimulation that could affect effector all $\mathrm{T}$ cells including Th1, Th2, and Th17 [13]. Supposedly after the administration of immunotherapy + placebo for 14 weeks, the number of Th17 cells would decrease due to increased activity of Treg cells, but instead in this study, from 7 samples that treated plus placebo, 4 samples has increased number of Th17 cells and 3 samples has decreased number of Th17 cells. Although not statistically significant, but when viewed more closely the data obtained, the mean number of Th17 cells post-treatment was lower than before treatment. From 4 samples which the Th17 cells were increased, 2 samples had persistent asthma and 2 samples suffered from intermittent asthma with IgE levels higher than other samples. This is consistent with study of Liu et al (2012) which states that the number of Th17 cells would be higher in allergic asthma with higher IgE levels. Sixty adult patients with bronchial asthma and 30 healthy human control were sequentially enrolled in that study. The production of IL-17 was measured by enzyme-linked immunosorbent assay (ELISA) and fluorescent quantitative polymerase chain reaction (qPCR), respectively. The correlation between expression of IgE and IL-17 was analyzed. It was found that IL-17 was significantly up-regulated in bronchial asthma in comparison to the health control on mRNA level, and serum levels of IL-17 and IgE in bronchial asthma were significantly higher than those in health control, respectively $(\mathrm{P}<0$. 001). Significant positive correlation in bronchial asthma were found between expression of IL-17 and $\operatorname{IgE}(r=0.7082, \mathrm{P}=0.0418)$. The present study implied that expressions of IL17 and IgE play an important role in the development of bronchial asthma [34].

In the previous studies mentioned that the number of Th17 cells was also associated with the degree of severity of asthma. In severe asthma patients found an increasing number of Th17 cells in their airways that correlated with increased neutrophil infiltration, production of the chemokine IL-8, and the degree of airway hyperresponsiveness [35-37]. No studies that compare the number of Th17 cells in mild asthma (between intermittent and mild persistent asthma), but from the definition, persistent asthma is more severe than intermittent asthma and also a longer duration of illness, so the number of Th17 cells would be higher on persistent rather than intermittent asthma. In addition the results of a positive skin prict test not only on the HDM can also affect the number of Th17 cells. Yamamoto et al (2010) stated that the number of Th17 cells was higher in patients with asthma who are allergic to HDM and food if compared with HDM alone [38]. In group 1 , the 2 samples that had increased the number of Th17 cells suffered from HDM and food allergies. Giving immunotherapy alone may indeed be less effective so that it is important to takes immunomodulatory such as Nigella sativa or probiotics as an adjuvant.

In the immunotherapy plus Nigella sativa group, the mean percentage of Th17 cells was lower than other groups. The mean number of Th17 cells was lower after treatment than before treatment, but the statistical analysis found no significant differences. Two previous studies mention about Nigella sativa beneficial in improving symptoms of asthma and allergic rhinitis [21,22]. Both of that study used Nigella sativa seed oil. Subijanto \& Diding (2008) also stated that Nigella sativa seed oil can reduce the degree of airway inflammation comparable to $3^{\text {rd }}$ generation antihistamines in murine models of asthma [39]. Nigella sativa can increase the number of lymphocytes TCD4 ${ }^{+} \mathrm{CD} 25^{+} \mathrm{FoxP} 3{ }^{+}$and CD8 ${ }^{+} \mathrm{T}$ lymphocytes as well as decrease the amount of CD4 + T lymphocytes [40,41]. No studies explained about the effects of Nigella sativa on the number of Th17 cells. Administration of Nigella sativa may increase the activity of Treg cells that secrete cytokines IL-10 and TGF- $\beta$ that can inhibit other effector T cell including Th17 cells. By administering immunotherapy plus Nigella sativa for 14 weeks, the number of Th17 cells will reduce. In group 2 (group that treated with immunotherapy plus Nigella sativa), 3 (37\%) samples showed an increasing number of Th17 cells and $5(63 \%)$ samples showed reduced number of Th17 cells compared to that before treatment. All samples with decreased number of Th17 
cells had lower levels of IgE. This may cause the value of the average number of Th17 cells in the group with lower IgE levels tend to be lower. Administration of Nigella sativa as an adjuvant immunotherapy was not statistically significant, but the mean number of Th17 cells is lower than the other treatment groups.

In immunotherapy plus probiotic group, 6 samples have increased number of Th17 cells and 2 samples have decreased number of Th17 cells. This result was not statistically significant, so it can not be used to make a conclusion that probiotics are not useful as an adjuvant immunotherapy. The use of probiotics in the treatment of allergic diseases is based on the ability of probiotics modulate toll-like receptor and antigen recognition proteoglycans of enterocytes, which activates dendritic cells and enhance the Th1 cell response, thereby decreasing Th2 cell response [18]. Probiotics can induce the development of Treg cells that will produce TGF- $\beta$ and IL-10 and produce a state of homeostasis by inhibiting cytokine of Th1 and Th2 cells [42]. The effect of probiotics on Th17 cells is not yet widely studied. Bifidobacterium infantis, a probiotic species can inhibit the production of IL-17 and TGF- $\beta$ stimulates formation, IL-6, and IL-10 [43]. Probiotics as an adjuvant in HDM spesific immunotherapy is effective in reducing the symptoms of asthma [31]. Oppositely, in this study, the mean number of Th17 cells after treatment is higher than before treatment. In this study, among the six samples that have increased number of Th17 cells, 4 samples were persistent asthma, 1 sample has high levels of IgE and 1 sample suffered from HDM and food allergies. As has been mentioned above that the number of Th17 cells tend to increase in patients with more severe asthma, high level of IgE and allergy more than one allergen (multiple allergen).

The study about combination of Nigella sativa and probiotics as an adjuvant immunotherapy has not been done. Based on the results of previous studies, probiotics and Nigella sativa should reduce the number of Th17 cells primarily due to an increase in the number of Treg cells. But this study showed precisely the opposite. These results also can not be used to make a conclusion that the combination of administration of Nigella sativa and probiotics did not benefit as adjuvant immunotherapy. Five samples

increased the number of Th17 cells, 3 samples had persistent asthma and 2 samples with high level of $\mathrm{IgE}$, so the number of Th17 cells was high from the beginning and tends to increase. It is required a longer observation so that the data can be analyzed better. Another possible mechanism is an increase in Treg cell activity will increase spending TGF- $\beta$ which can act as double effector substance as a pro-inflammatory or antiinflammatory cytokine. The combination of TGF- $\beta$ and IL- 6 will trigger the differentiation of naïve T cells into Th17 cell [44].

Th17 cells can produce IL-17 that induces bronchial fibroblasts, increases the expression of several other mediators such as IL-6, GM-CSF, CXCL8, PGE2 that acts on the local inflammatory airway and cause airway remodeling. The airway remodeling process cause the airways wall thickening, sub-epithelial fibrosis, hypertrophy and hyperplasia of airway and easy process that implicates angiogenesis airway obstruction and the onset of acute asthma attacks in patients [5,45]. Therefore, patients with persistent asthma with or without higher level of IgE, suffered from multiple allergen allergic, require more attention in order to be well controlled asthma and airway remodeling process can be inhibited.

The result showed that after administration of immunotherapy in mild asthmatic children, the clinical symptom was no significant difference with those before treatment $(\mathrm{p}=0.062)$. Its contrast to some previous studies, such the study from Abramson et al (1999) which states that the administration of specific HDM immunotherapy showed an improvement of clinical symptoms [46]. The use of sublingual immunotherapy was effective for two years and significantly reduced symptoms of mild and moderate asthma in HDM allergic children [47]. However, other studies mention that there can be a failure of about $24 \%$ in the use of immunotherapy for mild asthma and when combined with inhalation corticosteroids or other immunomodulatory, then success can be increased up to $100 \%$ [48].

In immunotherapy plus Nigella sativa group, it was obtained a very significant difference of clinical scoring ACT between before and after treatment $(\mathrm{p}=0.001)$. There was an increasing number of clinical scoring ACT after treatment compare to before treatment. The results was consistent with the Ahmed et al (2010) who mentions an improvement in peak expiratory flow rate (PEFR) and clinical symptoms after administration of Nigella sativa in 5-15 years old children [24]. The administration of Nigella sativa in allergic rhinitis patients receiving HDM specific immunotherapy showed an increase of immunotherapy efficacy because of increased activity of Treg cells [32].

In immunotherapy plus probiotic group also found significant differences in the mean number of clinical scoring ACT before and after treatment $(p=0.004)$. This is consistent with Irmawati et al $(2008)$ which states that the administration of sublingual specific HDM immunotherapy in combined with probiotics can improve clinical scoring in mild asthmatic children [31]. The Administration of probiotics combined with immunotherapy can stimulate dendritic cell maturation and increased levels of IL-10 that have antiinflammatory effects and induce Treg cell activity that can reduce the clinical symptoms of an allergic reaction $[49,50]$. The same result also found in immunotherapy plus Nigella sativa plus probiotic group. It can be made the conclusion that the administration of immunotherapy alone, immunotherapy plus Nigella sativa, 
immunotherapy plus probiotic, and immunotherapy plus Nigella sativa plus probiotics can improve the clinical scoring in mild asthmatic children. Longer observation is needed until the maintenance phase of immunotherapy to see the effect of various adjuvant immunotherapy in the number of Th17 cells.

The Statistical analysis showed that there was a significant relationship between the number of Th17 cells with the ACT in four groups. From these results it can be concluded that there is a reverse relationship between the number of Th17 cells and the number of ACT. There was 29 samples suffered from increased clinical scoring ACT, 1 sample with reduced of ACT and 1 sample does not increase or decrease of ACT. Eighteen samples have increased the number of Th17 cells and 11 samples has decreased the number of Th17 cells. This is not in accordance with the statistical results above that there was a reverse relationship between the number of Th17 cells and clinical scoring ACT. Supposedly if there is an increase in the number of Th17 cells, there will be a decrease in the number of ACT. These results could be due to the possibility, from 18 samples, 11 samples suffered from persistent asthma and 7 samples intermittent asthma. So the degree of severity of asthma tends to be more involved in clinical improvement of asthma. To get better results, a longer observation was needed, so the number of Th17 cells will increase in line with the duration of asthma. In this study, the samples already suffer from asthma more than 1 year. It can also contribute to an increase in the number of Th17 cells due process of airway remodeling that has occurred.

\section{Conclusions}

The administration of combination immunotherapy plus Nigella sativa plus probiotics did not reduce the number of peripheral blood Th17 cells in mild asthmatic children, but can improve clinical symptoms with an increasing of ACT scoring. A future study needs to be done with a longer observation (up to maintenance phase of immunotherapy) by using a mixture of Nigella sativa oil at a dose of more than one, to see a doseresponse relationship following administration of Nigella sativa + immunotherapy.

\section{References}

[1] Lazaar, A. \& Panettieri, R. 2000. Airway smooth muscle as a Regulator of Immune Respones and Bronchomotor tone. Clin Chest Med. 27(1): 53-69.

[2] Muro, S., Minshall, E.M., Hamid, Q.A. 2000. The Patology of Chronic Asthma. Clin Chest Med. 21 (3): $225-244$.

[3] Oboki, K., Ohno, T., Saito. H. \& Nakae, S. 2008. TH17 and Allergy. Allergology Int J. 57(1): 121-134.

[4] Cosmi, L., Liotta, F., Maggi, S., Romagnani, Annunziato, F. 2011. Th17 cells: New Players in Asthma Pathogenesis. Allergy J. 66 (4): 989-998.

[5] Wang, Y.H., Wills-Karp, M. 2011. The Potential Role of Interleukin-17 in Severe Asthma. Curr Allergy Asthma Rep. 11(1): 388394.

[6] Bahceciler, N., Isik, U., Barlan, IB., Baaran, M. 2001. Efficacy of Sublingual Immunotherapy in Children with Asthma and Rhinitis: a double-blind, placebo-controlled study. Pediatr Pulmonol. 32: 49-55.

[7] Ippoliti, F., De Santis. W., Volterrani, A. 2003. Immunomodulation during Sublingual Therapy in Allergic Children. Pediatr Allergy Immunol. 14 (1): 216-221.

[8] Nuhoglu, Y., Ozumut, SS., Ozdemir, C., Ozdemir, M., Erguven, M. 2007. Sublingual Immunotherapy to House Dust Mite in Pediatric Patients with Allergic Rhinitis and Asthma: A Retrospective Analysis of Clinical Course over a 3-Year Follow-up Period. J Investig Allergol Clin Immunol. 17(6): 375-378.

[9] Bot, CM., Moed, H., Berger, M., Roder, E., Groot, H., Jongste, JC et al. 2008. Randomized double-blind placebo-controlled Trial of Sublingual Immunoteraphy in Children with House Dust Mite Allergy in Primary Care; study design and recruitment. BMC Family Practice. 59 (9): 1-9.

[10] Eifan, A.O., Akkoc, T., Yildiz, A., Keles, S., Ozdemir, C., Bahceciller, N. et al. 2010. Clinical efficacy and immunological mechanisms of sublingual and subcutaneous immunotherapy in asthmatic/rhinitis children sensitized to house dust mite: an open randomized controlled trial. Clinical et Experimental Allergy. 40: 922-932.

[11] Yonekura, S., Okamoto, Y., Sakurai, D., Horiguchi, S., Hanazawa, T.,Nakano, A. et al. 2010. Sublingual Immunotherapy with House Dust Extract for House Dust-Mite allergic Rhinitis in Children. Allergology International. 59: 381-388.

[12] Nurhayati, R., Susanti, N., Barlianto, W. 2011. Outcome Of Subcutaneous Immunotherapy In Children With Astma And Rhinitis Allergy. Pediatr Indones. 51(4):76.

[13] Fujita, H., Soyka, M.B., Akdis, M., Akdis, C.A. 2012. Mechanisms of allergen-specific immunotherapy. Clinical and Translational Allergy. 2(2): 1-8.

[14] Sanders, ME. 2003. Probiotics: considerations for human health. Nutr Rev. 61: 91-99.

[15] Jang, S.-O., Kim, H.-J., Kim, Y.-J., Kang, M.-J., Kwon, J.-W., Sep, J.-H., Kim, H. Y., Kim, B.-J., Yu, J. \& Hong, S.-J. 2012. Asthma Prevention by Lactobacillus Rhamnosus in a Mouse Model is Associated With CD4+CD25+Foxp3+ T Cells. Allergy Asthma Immunol Res, 4, 150-156.

[16] Jinho, Yu., Jang, S., Kim, B.J., Song, Y.H., Kwon, J.W., kang, M.J. et al. 2010. The Effects of Lactobacillus rhamnosus on the Prevention of Asthma in a Murine Model. Allergy Asthma Immunol Res. 2 (3): 199-205.

[17] Endaryanto, A., Harsono, A., Subrata, L.A. 2009. Immunomodulatory effect of probiotic \& sublingual immunotherapy in asthmatic children. Folia Medica Indones. 45 (1): 14-21.

[18] Yue-Sheng, C., Ren-Long, J., Yen-Lin, L., Hsin-Hun, C., Jiu-Yao, W. 2010. Randomized Placebo-Controlled Trial of Lactobacillus on Asthmatic Children with Allergic Rhinitis. Pediatric Pulmonology. 45: 1111-1120.

[19] Gilani, A., Aziz, N., Khurram, I., Chaudhary, K., Iqbal, A. 2001. Bronhodilator, spasmolytic and calcium antagonist activities of Nigella sativa seeds (Kalonji): a traditional herbal product with multiple medicinal uses. J Pak Med Assoc. 51 (3): 115-120.

[20] Saleem, M.L. 2005. Immunomodulatory and therapeutic properties of the Nigella sativa L. seed. International Immunopharmacology. 5: 1749-1770.

[21] Kalus, U., Pruss, A., Bystron, J., Jurecka, M., Smekalova, A., Lichius, J.J, et al. 2003. Effect of Nigella sativa (black seed) on subjective feeling in patients with allergic diseases. Phytother Res. 17:1209-1214. 
[22] Boskabady, M.H., Mohsenpoor, N., Takaloo, L. 2010. Antiasthmatic effect of Nigella sativa in airways of astmatic patients. Phytomedicine. 17: 703-713.

[23] Barlianto, W., Kusuma, C.HM.S., Widodo, A. 2012. Crude extract of black seed (Nigella sativa) can modulate TCD4+CD25+FoxP3+ lymphocytes in asthmatic mouse model. Paed Resp Rev. 13 (1): 554.

[24] Ahmed, J., Khan, R.A., Malik, M.A. A study of Nigella sativa oil in the management of wheeze associated lower respiratory tract illness in children. 2010. African Journal of Pharmacy and Pharmacology. 4 (7): 436-439.

[25] Nathan, R.A., Sorkness, C.A., Kosinski, M.A., Schatz, M., Marcus, P., Murray, J. 2004. Development of the Asthma Control Test: A survey for assessing asthma control. J Allergy Clin Immunol. 113 (1): 59-65.

[26] Liu A, Covar R, Spahn J, Leung D. 2007. Childhood Asthma in Kliegman R, et al (eds), Nelson Textbook of Pediatrics $18^{\text {th }}$ edition. Saunders Elsevier.p.953-970.

[27] Global Initiative For Asthma. 2010. Pocket Guide for Asthma Management and Prevention. (updated 2010). Ontario: Global Initiative for Asthma (GINA).

[28] Liu, A.H., Zeiger, R.S., Sorkness, C.A., Ostrom, N.K., Chipps, B.E., Rosa, K.et al 2010. The Childhood Asthma Control Test*: Retrospective determination and clinical validation of a cut point to identify children with very poorly controlled asthma. $J$ Allergy Clin Immunol. 126 (2): 267-273.

[29] Shi, Y., Tatavoosian, A.V., Aledia, A.S., george, S.C., Galant, P. 2012. Cut points for Asthma Control Tests in Mexican children in Orange County, California. Ann Allergy Asthma Immunol. 109 (1): 108-113.

[30] Isolauri, E., Arvola, T., Sutas, Y. 2000. Probiotics in the management of atopic eczema. Clin Exp Allergy. 30: 1604-1610.

[31] Irmawati, M., Endaryanto, A., Harsono, A. 2008. Role of sublingual immunotherapy and probiotics in clinical improvements of childhood asthma. Paediatr Indones. 48 (5):261-268.

[32] Isik, H., Cevikbas, A., gurer, U.S., Kiran, B. 2010. Potential Adjuvant Effects of Nigella sativa Seeds to Improve Spesific Immunotherapy in Allergic Rhinitis Patients. Med Princ Pract. 19: 206-211.

[33] Boskabady, M.H., Javan, H., Sajady, M., Rakhshandeh, H. 2007. The possible prophylactic effect of Nigella sativa seed extract in asthmatic patients. Fundamental \& Clinical Pharmacology. 21: 559-566.

[34] Liu H, Cheng H, Zhang Y, Hua S. 2012. Expression of interleukin 17 and IgE, and its significance in patients with bronchial asthma. African Journal of Pharmacy \& pharmacology.6(40):2828-31.

[35] Blaschitz, C \& Raffatellu, M 2010. Th17 Cytokines and the Gut Mucosal Barrier. Journal of Clinical Immunology. 30: $196-203$.

[36] Chakir, J., Shannon, J., Molet, S. 2003. Airway remodeling associated mediators in moderate to severe asthma: effect of steroids on TGF-beta, IL-11, IL-17, and type I and type III collagen expression. J Allergy Clin Immunol. 111: 1293-1298.

[37] Al-Ramli, W., Prefontaine, D., Chouiali, F. 2009. Th17-associated cytokines (IL-17A and IL-17F) in severe asthma. J Allergy Clin Immunol. 123:1185-1187.

[38] Yamamoto Y., Negoro T., Wakagi A., Hoshi A., Banham A. 2010. Participation of Th17 and Treg cells in pediatric bronchial asthma. Journal of health science. 56(5):589-97.

[39] Subijanto \& Diding. 2008. Pengaruh minyak biji jinten hitam (Nigella sativa) terhadap derajat inflamasi saluran napas. Maj Kedokt Indon. 58(6):200-204

[40] Barlianto, W., Kusuma, C.HM.S., Widodo, A. 2012. Crude extract of black seed (Nigella sativa) can modulate TCD4+CD25+FoxP3+ lymphocytes in asthmatic mouse model. Paed Resp Rev. 13 (1): 554.

[41] Kusuma, C.HM.S., Barlianto, W., Widodo, A., Sudiarto, S. 2012. Crude extract of black seed (Nigella sativa) can modulate TCD4+ and CD8+ lymphocytes in asthmatic mouse model. Paed Resp Rev. 13 (1): 555.

[42] Weid, T, Bulliard, C \& Schiffrin, E 2001. Induction by Lactic Acid Bacterium of a Population of Cd4+ T Cells with Low Proliferative Capacity That Produce Transforming Growth Factor B and Interlaukin-10. Clinical and Diagnostic Laboratory Immunology. 696-701.

[43] Tanabe, S, Kinuta, Y \& Saito 2008. Bifidobacterium Infantis Suppresses Proinflammatory Interleukin-17 Production in Murine Splenocytes and Dextran Sodium Sulfate-Induced Intestinal Inflammation. International Journal of Molecular Medicine. 22: 181-5

[44] Sansonetti, P \& Di Santo, J 2007. Debugging How Bacteria Manipulate the Imun Response. Journal of Immunology. 149-61

[44] Molet, S., Hamid, Q., Davoine, F. 2001. IL-17 is increased in asthmatic airways and induces human bronchial fibroblasts to produce cytokines. J Allergy Clin Immunol. 108: 430-438.

[46] Abramson, M., Puy, R., Weiner, J. 1999. Immunotherapy in asthma:an updated systemic review. Allergy. 54: 1022-1041.

[47] Bousquet, J., Jeffery P.K., Busse, W.W., Johnson, M., Vognola, A.M. 2000. Asthma from bronchoconctriction to airways inflammation and remodeling. Am J Respir Crit Care Med .161: 1720-1745.

[48] Harsono, A. 2004. Modulation of immune response in the use of long term corticpsteroid inhalation in childhood asthma receiving immunotherapy. Disertation, airlangga University, Surabaya, Indonesia.

[49] Lammers, K.M., Brigidi, P., Vitali, B., Gionchetti, P., Rizzello, F., Caramelli, E. et al. 2003. Immunomodulatory effects of probiotic bacteria DNA: IL-1 and IL-10 response inhuman peripheral blood mononuclear cells. FEMS Immunol Med Microbiol. 38: $165-172$.

[50] Borchers, A.T., Selmi, C., Meyers, F.J., Keen, C., Gershwin, M.E. 2009. Probiotics and immunity. J Gastroenterol. 44: 26-46. 